\title{
What we Learn when Designing with Marginalised Children
}

\begin{tabular}{|c|c|}
\hline Seray Ibrahim & Erin Beneteau \\
\hline University College London & University of Washington \\
\hline London, UK & Seattle, US \\
\hline s.ibrahim@ucl.ac.uk & ebenet@uw.edu \\
\hline Emeline Brulé & Oussama Metatla \\
\hline University of Sussex & Bristol University \\
\hline Falmer, UK & Bristol, UK \\
\hline e.t.brule@sussex.ac.uk & o.metatla@bristol.ac.uk \\
\hline Laura Benton & Nikoleta Yiannoutsou \\
\hline University College London & European Commission \\
\hline London, UK & Seville, Spain \\
\hline I.benton@ucl.ac.uk & nikoleta.giannoutsou@ec.europ \\
\hline Anthony Hornof & Katta Spiel \\
\hline University of Oregon & KU Leuven \& Universität Wien \\
\hline Eugene, US & Leuven, BE \& Vienna, AT \\
\hline hornof@cs.uoregon.edu & katta.spiel@kuleuven.be \\
\hline
\end{tabular}

Permission to make digital or hard copies of part or all of this work for personal or classroom use is granted without fee

provided that copies are not made or distributed for profit or commercial advantage and that copies bear this notice and the

full citation on the first page. Copyrights for third-party components of

this work must be honored. For all other uses, contact

the owner/author(s).

IDC '20 Extended Abstracts, June 21-24, 2020, London, United Kingdom. (C) 2020 Copyright is held by the owner/author(s).

ACM ISBN 978-1-4503-8020-1/20/06.

DOI: https://doi.org//10.1145/3397617.3398067

\begin{abstract}
Designing with marginalised children often produces detailed insights about their lives and communities. Whilst it is possible to extract methodological and artefact-centred knowledge from existing design cases, it can be difficult to utilise and build on some of the more complex and multifaceted issues that these generate, for instance, how researcher decisions inform design outcomes. In this workshop, we invite researchers to reflect on the insights design case studies with marginalized children offer to the larger Children-Computer Interaction (CCI) community. Our goals are to reflect on what kinds of insights are generated; what we as design researchers and practitioners would have wanted to know prior to undertaking such work, and; to identify ways of communicating these insights.
\end{abstract}

\section{Author Keywords}

Inclusive Design; Marginalisation; Participatory Research; Methodology.

\section{CSS Concepts}

- Human-centered computing Interaction design; Interaction design process and methods; Participatory design; 


\section{Background}

Interaction designers are increasingly interested in designing for marginalised children. We use the term 'marginalised children' to refer to children and young people whose perspectives tend to be neglected in traditional research and society at large and can include but is not limited to issues surrounding class, disability, racialisation, abuse or hospitalisation [13]. Design work in these contexts raises a number of challenges, especially as this body of research often has transformative aims to produce positive social change. Subsequently, we find an increasing number of design work involving marginalised children $[3,5]$. However, such research requires maintaining a delicate balance between ensuring their right to participation and ensuring the knowledge thus produced does not unintentionally create harm [17].

Research with marginalised children within the Children-Computer Interaction (CCI) field has mainly made methodological (e.g. $[7,8]$ ), political (e.g. $[1,12])$, reflective (e.g. [6]) and artifact contributions (e.g., [16]). However, little research has considered how children's involvement can inform wider design research issues or contribute to related work from different fields such as Childhood Studies, or Learning and Rehabilitation Sciences.

This is not a new concern in CCI [20]. In reviewing all papers presented at IDC between 2003-2016, [2] identified that the vast majority of submitted papers discussed the design of an artefact and its evaluation. The authors call for creating intermediate level knowledge in the form of 'strong concepts' which is broadly defined as knowledge that has generative qualities in that it can be appropriated by different design teams in new instantiations [9]. In the case of CCI and design research for marginalised groups, little such transferable strong concepts have been reported. Yet, this would support designing for a more inclusive future.

We call for researchers to submit case studies and position papers with the following aims:

- Developing strong design concepts from case-studies participants have engaged in.

- Reflecting on epistemological, methodological and theoretical aspects participants would have wanted to know prior to engaging in design work with marginalised groups.

- Generating practical guidance in the form of descriptions about the kinds of existing design perspectives, methodological issues and other transferable insights that underpin design work through example cases that can provide a road map for others.

\section{Topics of Interest}

In this section, we reflect on existing attempts to transfer findings from CCI with marginalised groups to other areas, which authors could consider in their contributions. This workshop is intended to be a space for discussing the potential impact of design research with marginalised children.

The 'how' and 'what' to design

Existing design cases have contributed adaptations for designing technologies based on specific marginalised children's groups (e.g. [4,19,23]). For example, [23] showed that methodological decisions about how to 
understand children's interests significantly inform what was designed. Similarly, [10] used observation through a microanalysis of multimodal communication to understand communication practices involving children with severe speech and physical impairments, their social groups and existing augmentative and alternative communication (AAC) technologies. Submitted cases could discuss how methods influence what is being designed and what effect this has on the lives of the children and communities who are involved.

Terminology and positioning marginalization Marginalisation can take on different forms. For example, a notable amount of PD work concerns with people who have physical, sensory and cognitive impairments [14]. Definitions and understanding of disability greatly impact the resulting technologies [18]. Some recent work has taken a more active stance in being explicit about the values and contexts that guide design work $[3,6]$, yet different perspectives bring with them tensions in how design research ultimately connects with and is relevant to the lives of children and their communities. This likely affects other identity markers as well (see, e.g., for race [21]), though those are arguably even more under-researched. When attempting to advance an emancipatory PD agenda without considering how marginalisation is seen by local funders, policies and provisions, there is a risk that researcher priorities can be seen as idealistic (see [11]). Potential submissions could discuss how design researchers might consider the wider constraints surrounding designing with marginalised children, and how to access such information.

\section{Informed Consent}

At the time of preparing this workshop proposal, we reflect on the geographical and contextual discourses surrounding the IDC conference that was due to be held in London, UK in 2020. Informed decision making of all kinds is a prominent discussion point in the UK's national politics. Considering the local context and reflecting on the planned conference venue, the site of the British Medical Council (BMA), we consider how other communities could learn from the ways that interaction design researchers have creatively approached informed consent. The workshop offers opportunities for considering: how might the healthcare system and other institutions utilize practices from the CCI community for discussing consent?

Theoretical insights about a given concept PD work with marginalised children often uses ethnographic and reflexive methods for investigating a given phenomenon, e.g. interpersonal communication [11], social-emotional learning [15], peer support [22]. Through their findings, design cases often produce new and detailed understandings that contribute to how such phenomena manifest. For example, in the case of investigating social emotional learning, [15] contributed rich perspectives on how this is taught in primary school settings. The broader CCI field could make use of these new theoretical insights but rarely does. Moreover, we should consider how these insights can be outwardly communicated within related fields.

Working in new and varied contexts with marginalised children involves understanding local cultures and practices surrounding children's lives which can be very different to the experiences of design researchers. We invite new and established researchers to reflect on 
how their perspectives shape their design research projects with marginalised children, and on how to develop theoretical frameworks for understanding the ramifications of their decisions.

\section{Organisers}

- Main contact: Seray Ibrahim is a research fellow at the UCL Institute of Education and a SpeechLanguage Therapist. Seray's PhD research investigated communication in children with severe speech and physical impairments with the view to informing ways of designing technologies for communication.

- Émeline Brulé is a Lecturer at University of Sussex. Her research focuses on inclusive design.

- Laura Benton is a research associate at the UCL Institute of Education. Her research focuses on education technology design for children and she has worked on several projects using design approaches such as participatory design and design-based research, including iRead, iLearnRW and ScratchMaths.

- Anthony Hornof is a Professor of Computer and Information Science at the University of Oregon. He works in two very different areas of human-computer interaction: (a) predicting aspects of usability through the development of computational psychological models of the human as an information processor, and (b) developing assistive technology with and for people with severe cognitive and motor impairments.

- Oussama Metatla is a Senior Lecturer and EPSRC Senior Research Fellow in the Department of Computer Science at the University of Bristol. His research interests include multisensory interaction, sensory and cognitive impairments and co-designing with and for people with disabilities. He currently leads a project focusing on inclusive educational technology for mixed ability groups in mainstream schools.

- Erin Beneteau is a PhD candidate at the iSchool, University of Washington and a Speech-Language Therapist. Her research interests include communication interactions between children, their families, and technologies. Her thesis research focuses on creative pursuits and people who use assistive technologies.

- Nikoleta Yiannoutsou is a Scientific Officer at the Joint Research Centre of the European Commission and a honorary Senior Research Fellow at the UCL Knowledge Lab. Her research focuses on the design of digital technologies for children's learning. Her recent work at UCL involved design based research of multisensory technologies with visually impaired children.

- Katta Spiel is a Postdoctoral Researcher in Playful Physical Computing with KU Leuven and University of Vienna, where they investigate the play preferences of neurodivergent people. Their broader research agenda centers marginalised perspectives in design with a focus on gender and disability.

\section{Website}

We will create a page for this workshop on the website http://www.inclusiveeducation.tech/ which centralizes resources about designing with and for disabled and otherwise marginalised children. 


\section{Pre-Workshop plans}

A call for participation will be shared on social media, and relevant mailing lists. This workshop partly spawns from previous efforts to build resources about designing inclusive technologies for education for the CCI community (http://www.inclusiveeducation.tech/). We will also reach out to researchers in related field, such as the research centre of childhood studies, University of Sussex and at UCL. Therefore, we estimate we will be able to attract this growing community, with an attendance of at least 15 participants. The workshop will be advertised at the beginning of March, with a submission deadline mid-May. Submissions will be reviewed by the organisers and invited reviewers. Following the alt-chi model, neither reviews nor articles are anonymised. Authors will receive notification by the end of May and will be asked to register for the workshop.

\section{Workshop Structure}

This workshop would take half a day and will take place online both synchronously and asynchronously as part of the virtual format of the IDC conference. Ahead of the workshop, we will summarise received submissions and the issues they present by drawing out insights

- 13h-13h10: Introduction and the goals of the workshop

- 13h10-14h10: Attendees will work in groups to present design contexts and review each of the cases against the themes of the workshop.

- 14h10-14h40: Break

- 14h40-15h25: Attendees will discuss the insights, challenges and possibilities of the design contexts reviewed in the first activity.
- 15h25-15h50: Presentation of attendees' work, and group discussion on plans for collating the discussed examples and how such resources might be centralised, e.g. through the workshop website, planning for co-writing articles/research projects.

- 15h50-16h00: Conclusions

\section{Post-Workshop plans}

We will share our insights on the workshop website, on http://www.inclusiveeducation.tech/, as well as a dissemination blogpost for designers more widely through Medium. Our aim is to encourage participants to collaboratively write research papers about the themes discussed during the workshop. To support this, the organisers will themselves lead the writing of at least a journal paper on this topic and invite all interested participants to collaborate. This is in line with previous efforts from this community, which has resulted in research publications at $\mathrm{CHI}$ or in other journals with early career researchers. Through these activities, we also aim to strengthen an existing SIG within the CHI community ('Evaluating Technologies with and for Disabled Children').

\section{Call for participation}

This is a half day workshop organised as part of the IDC 2020 conference held online. In this workshop, we aim to provide a space for reflecting on and documenting different types of knowledge for the CCI community that can be generated in design work with marginalised children. We invite academics and practitioners with an interest in working in these contexts to submit an expressions of interest form, describing their experiences of design work with marginalised children. Participants are invited to 
consider works that have most informed or had the biggest impact on their own work, what they learned from their own encounters, and a reflection on what would have been helpful to know before undertaking their work. These papers should be submitted via the workshop website (inclusiveeducation.tech). They will be reviewed by committee members based on relevance to the workshop and the potential for contributing to discussions. Accepted papers will become the basis of workshop discussions. At least one author of each accepted position paper must attend the workshop and all participants must register for both the workshop and the main conference.

\section{References}

1. Meryl Alper. 2017. Giving voice: mobile communication, disability, and inequality. MIT Press, Cambridge, MA.

2. Wolmet Barendregt, Olof Torgersson, Eva Eriksson, and Peter Börjesson. 2017. Intermediate-Level Knowledge in Child-Computer Interaction: A Call for Action. Proceedings of the 2017 Conference on Interaction Design and Children, ACM, 7-16.

3. Laura Benton and Hilary Johnson. 2015. Widening participation in technology design: A review of the involvement of children with special educational needs and disabilities. International Journal of Child-Computer Interaction 3-4: 23-40.

4. Laura Benton, Asimina Vasalou, Rilla Khaled, Hilary Johnson, and Daniel Gooch. 2014. Diversity for design: a framework for involving neurodiverse children in the technology design process. ACM Press, 3747-3756.
5. Peter Börjesson, Wolmet Barendregt, Eva Eriksson, and Olof Torgersson. 2015. Designing technology for and with developmentally diverse children: a systematic literature review. Proceedings of the 14th International Conference on Interaction Design and Children, ACM Press, 79-88.

6. Emeline Brulé and Katta Spiel. 2019. Negotiating Gender and Disability Identities in Participatory Design. Proceedings of the 9th International Conference on Communities \& Technologies Transforming Communities, Association for Computing Machinery, 218-227.

7. Aurora Constantin, Juan Pablo Hourcade, Annalu Waller, et al. 2019. Pushing the Boundaries of Participatory Design with Children with Special Needs. Proceedings of the Interaction Design and Children - IDC '19, ACM Press, 697-705.

8. Mona Leigh Guha, Allison Druin, and Jerry Alan Fails. 2008. Designing with and for children with special needs: an inclusionary model. ACM Press, 61.

9. Kristina Höök and Jonas Löwgren. 2012. Strong concepts: Intermediate-level knowledge in interaction design research. ACM Transactions on Computer-Human Interaction 19, 3: 1-18.

10. Seray B. Ibrahim. 2020. Communication and NonSpeaking Children with Physical Disabilities: Opportunities and Reflections from DesignOriented Research. Doctoral Thesis, UCL.

11. Seray B. Ibrahim, Asimina Vasalou, and Michael Clarke. 2018. Design Opportunities for AAC and Children with Severe Speech and Physical Impairments. Proceedings of the $2018 \mathrm{CHI}$ 
Conference on Human Factors in Computing Systems, ACM, 227:1-227:13.

12. Roisin McNaney, Madeline Balaam, Kevin Marshall, et al. 2013. Designing for and with children with special needs in multiple settings. Proceedings of the 12th International Conference on Interaction Design and Children - IDC '13, ACM Press, 603.

13. Johanna Sköld and Kaisa Vehkalahti. 2016. Marginalized children: methodological and ethical issues in the history of education and childhood. History of Education 45, 4: 403-410.

14. Karin Slegers, Pieter Duysburgh, and Niels Hendriks. 2014. Participatory design with people living with cognitive or sensory impairments. $\mathrm{CHI}$ '14 Extended Abstracts on Human Factors in Computing Systems, Association for Computing Machinery, 49-52.

15. Petr Slovák, Christopher Frauenberger, and Geraldine Fitzpatrick. 2017. Reflective Practicum: A Framework of Sensitising Concepts to Design for Transformative Reflection. Proceedings of the 2017 $\mathrm{CHI}$ Conference on Human Factors in Computing Systems, ACM, 2696-2707.

16. Katharina Spiel, Julia Makhaeva, and Christopher Frauenberger. 2016. Embodied Companion Technologies for Autistic Children. Proceedings of the TEI '16: Tenth International Conference on Tangible, Embedded, and Embodied Interaction TEI '16, ACM Press, 245-252.

17. Katta Spiel, Emeline Brulé, Christopher Frauenberger, Gilles Bailly, and Geraldine Fitzpatrick. 2018. Micro-ethics for participatory design with marginalised children. Proceedings of the 15th Participatory Design Conference on Full Papers - PDC '18, ACM Press, 1-12.

18. Katta Spiel, Christopher Frauenberger, Os Keyes, and Geraldine Fitzpatrick. 2019. Agency of Autistic Children in Technology Research-A Critical Literature Review. ACM Trans. Comput.-Hum. Interact. 26, 6: 38:1-38:40.

19. Katta Spiel, Laura Malinverni, Judith Good, and Christopher Frauenberger. 2017. Participatory Evaluation with Autistic Children. ACM Press, 5755-5766.

20. Olof Torgersson, Tilde Bekker, Wolmet Barendregt, Eva Eriksson, and Christopher Frauenberger. 2019 Making the Child-computer Interaction Field Grow Up. Interactions 26, 2: 7-8.

21. Greg Walsh. 2018. Towards equity and equality in American co-design: a case study. Proceedings of the 17th ACM Conference on Interaction Design and Children, ACM, 434-440.

22. Pontus Wärnestål, Petra Svedberg, and Jens Nygren. 2014. Co-constructing child personas for health-promoting services with vulnerable children Proceedings of the 32nd annual ACM conference on Human factors in computing systems - CHI '14, ACM Press, 3767-3776.

23. Cara Wilson, Margot Brereton, Bernd Ploderer, and Laurianne Sitbon. 2019. Co-Design Beyond Words: "Moments of Interaction" with Minimally-Verbal Children on the Autism Spectrum. Proceedings of the 2019 CHI Conference on Human Factors in Computing Systems - CHI '19, ACM Press, 1-15. 